\title{
Erectile Dysfunction among Diabetic Men in Two Medical Centers in Burkina Faso: Epidemiological, Diagnosis and Therapeutic Aspects
}

\author{
Timothée Kambou ${ }^{1}$, Cyprien Zaré ${ }^{1}$, Abdoul Karim Paré2, Adama Ouattara ${ }^{1}$, \\ Youombèviel Ludovic Somé ${ }^{1}$, Bakary Gustave Sanon ${ }^{3}$ \\ ${ }^{1}$ Department of Urology, Sanon Souro Teaching Hospital, Bobo Dioulasso, Burkina Faso \\ ${ }^{2}$ Department of Urology, Hubert K MAGA National TeachingHospital, Cotonou, Bénin \\ ${ }^{3}$ Department of General Surgery, Sanon Souro Teaching Hospital, Bobo Dioulasso, Burkina Faso \\ Email: timothee.kambou@gmail.com, zcyprien@yahoo.fr, boupare@yahoo.fr, \\ adamsouat1@hotmail.com, ludovicsom@yahoo.fr, baksanon@yahoo.fr
}

Received November 17, 2013; revised December 17, 2013; accepted December 24, 2013

Copyright (c) 2014 Timothée Kambou et al. This is an open access article distributed under the Creative Commons Attribution License, which permits unrestricted use, distribution, and reproduction in any medium, provided the original work is properly cited. In accordance of the Creative Commons Attribution License all Copyrights (C) 2014 are reserved for SCIRP and the owner of the intellectual property Timothée Kambou et al. All Copyright (C) 2014 are guarded by law and by SCIRP as a guardian.

\section{ABSTRACT}

Objective: To study erectile dysfunction in diabetic patients seen in two clinics in the city of Bobo-Dioulasso, Burkina Faso. Materials and Methods: A prospective cross-sectional descriptive study was conducted at the Sourô Sanou Teaching Hospital (CHUSS) and the Saint Leopold clinic in Bobo-Dioulasso, from March 1 to September 1, 2012. A total of 107 patients data were collated and analysed, which was then grouped into two: the ED group, designating patients with erectile dysfunction and the NED group consisting of those patients without. The sample comprised of 61 patients with types 1 and 2 diabetesand were aged between 25 - 70 years. The IIEF-5 was used to evaluate erectile dysfunction. Results: The prevalence of erectile dysfunction was $57 \%$. The average age of patients was $54.4 \pm 8.3$ years. All patients with ED had type 2 diabetes. The mean disease duration of diabetes was $7.2 \pm 6$ years. Erectile dysfunction was severe in $32.8 \%$ of cases, moderate in $31.1 \%$ of cases and mild in $36.1 \%$. Its severity was significantly associated with glycated hemoglobin, triglycerides and BMI. Phosphodiesterase types 5 (PDE5) inhibitors were found to be effective in the treatment of erectile dysfunction with a satisfactory therapeutic response in $77.4 \%$ of users. Conclusion: Erectile dysfunction is a common complication in diabetic patients. Its occurrence and severity are influenced by several factors. The potential presence of this disorder should be assessed due to its negative impact on quality of life. Phosphodiesterase type 5 inhibitors are an effective treatment modality in diabetic patients.

\section{KEYWORDS}

Erectile Dysfunction; Diabetes; Phosphodiesterase Type 5 Inhibitors; Bobo-Dioulasso

\section{Introduction}

Diabetes is a serious public health problem, which according to the International Diabetes Federation, occurs in 2\% - 3\% of the adult population in Burkina Faso [1]. Microangiopathy is one of its many chronic complications, and can lead to erectile dysfunction. The prevalence of erectile dysfunction among patients with diabetes indiabetics is approximately $16 \%$ to $95.5 \%$ worldwide [2,3]. Despite the efficacy and availability of phospho-diesterase type 5 inhibitors and intracavernous injections in the treatment of erectile dysfunction in diabetic patients [4], it is still at a boo subject in frequently broached by patients.

With the growing number of diabetic patients in Burkina Faso, it is becoming increasingly relevant to study this population. Better quantifying the epidemiology, diagnostic modalities and therapeutic options will contribute to a better understanding of this phenomenon and how to improve its management.

\section{Patients and Methods}

We undertook descriptive study of patients seen in the Departmentof Internal Medicine at the SourôSanou 
Teaching Hospital (CHUSS) and the Saint Leopold clinic in the city of Bobo Dioulasso, for a period of six (06) months going from March 1, 2012 to September 1, 2012. We recruited 107 patients and divided into two groups: the ED, group, comprised of patients who had erectile dysfunction, and the NED group, made up of patients who did not. A total of 61 men between the ages of 25 to 70 with type 1 and 2 diabetes inwhomthe diagnosis of erectile dysfunction (ED) was made following consultation.

The variables studied were age, marital status, diabetic history, medical history, characteristics of ED, other sexual disorders found on additional assessments, treatments attempted and efficacy of attempted treatments. The short form of the International Index of Erectile Function (IIEF-5) [5] was used to assess erectile function. It includes five major parts, each with five questions listed 1 to 5 , and designed to explore quality of sex, sexual desire and overall satisfaction with sex. For interpretation, as core scale is established with the following corresponding values: severe erection disorder (score of 5 to 10$)$, moderate (11 - 15), mild (16 - 20), or normal erectile function (21 - 25).

ED treatment modalities employed included sildenafil 50 - $100 \mathrm{mg}$ daily, tadalafil 10 - $20 \mathrm{mg}$ once daily or yohimbine $15 \mathrm{mg}$ daily. Chi-squaretest was used for categorical variables and analysis of variancetest (ANOVA) for quantitative variables. The significance levelwas set at $\mathrm{p}<0.05$. Informed consent was obtained from each man before the start of this study, as well as the approval of the local ethics committee authorizing this work.

The Chi-square test was used for categorical variables. Statistical significance was set at $\mathrm{p}<0.05$.

\section{Results}

Of the 107 diabetic patients seen, 61 (57\%) reported erectile dysfunction (ED). The average age of patients was $54.4 \pm 8.3$ years, ranging from 34 years to 70 years. In our study, 102 (95.3\%) patients were married with 59 (57.8\%) having erectile dysfunction, and 43 (42.2\%) not presented $(\mathrm{P}=0.4)$. Among the married patients with ED, 35 (59.3\%) were monogamous and 24 (40.7\%) polygamous, while in the NED group, 31 (72.1\%) were monogamous and $12(27.9 \%)$ polygamous $(\mathrm{p}=0.3)$. All patients with ED had type 2 diabetes. The mean duration of diabetes was $7.27 \pm 6.01$ years, ranging from 3 weeks to 26 years. All patients were on dietary control; sulphonylureas were used by $37.6 \%$ (23) of patients, biguanides by $60.7 \%$ (37) of patients and18 patients (29.5\%) were on insulin. Other risk factors for ED are found in Table 1.

The mean duration of hypertension was $7.7 \pm 7.1$ years (range 2 months to 30 years). Diabetes was uncontrolled
Table 1. Prevalence of other risk factors for erectile dysfunction within the study population.

\begin{tabular}{ccccccc}
\hline & & \multicolumn{2}{c}{ ED } & \multicolumn{2}{c}{ NED } & P value \\
\hline \multirow{2}{*}{ Riskfactors } & & N & $\%$ & N & $\%$ & \\
& yes & $\mathbf{3 1}$ & $\mathbf{5 0 . 8}$ & $\mathbf{9}$ & $\mathbf{1 9 . 6}$ & \\
Hypertension & no & 30 & 49.2 & 37 & 80.4 & $\mathbf{0 . 0 0 0 9}$ \\
& yes & 4 & 6.6 & 2 & 4.3 & \\
Obesity by BMI & no & 57 & 93.4 & 44 & 95.6 & \\
& yes & 14 & 23 & 8 & 17.3 & \\
Tobacco & no & 47 & 77 & 38 & 82.6 & 0.6 \\
& yes & 14 & 23 & 11 & 23.9 & \multirow{2}{*}{ Alcohol } \\
& no & 47 & 77 & 35 & 76.1 & 0.9 \\
& yes & 20 & 32.8 & 27 & 58.7 & \\
Dyslipidemia & no & 41 & 67.2 & 19 & 41.3 & \\
\hline
\end{tabular}

in $43(70.5 \%)$ patients and hypercholesterolemia was observed in 13 (21.3\%) patients. Hypertrigly ceridemia was found in 8 patients (13.1\%) and abnormal electrocar diogram in 28 (51.8\%) patients.

It should be noted that only 16 (26.2\%) patients had already talked about erectile dysfunction with their doctors. The average duration of erectile dysfunction was 3.5 years, ranging from 3 months to 35 years. Onset of ED was gradual in 58 patients (95.1\%) and sudden in 3 patients $(4.9 \%)$. One (1.6\%) patient reported primary ED while 60 patients (98.4\%) reported secondary ED. Furthermore, 10 patients $(16.4 \%)$ reported difficulty initiating an erection and 51 (83.6\%) reported difficulty maintaining an erection. Erectile dysfunction was variable in 8 patients (13.1\%). Among them, five experienced variability based on different partners and three experienced variability due to time period. Indeed, these patients felt their erections improved with either a different partner or during a different time period. Spontaneous erections (nocturnal and/or diurnal) were maintained in 23 patients (37.7\%) and absent in 38 patients (62.3\%). Erectile dysfunction was severe in $32.8 \%$ of cases, moderate in $31.1 \%$ of cases and mild in $36.1 \%$. The association between certain patient characteristics and the severity of their erectile dysfunction is shown in Table 2.

The glycated hemoglobin, body mass index and triglyceride levels increased significantly with the severity of erectile dysfunction.

Regarding the impact of ED on quality of life, only 7 (11.5\%) patients reported living without problem with their erectile dysfunction, 22 (36.1\%) patients found it to be difficult and 32 (52.4\%) patients found it to be un- 
Table 2. Distribution of ED severity by patient characteristic.

\begin{tabular}{ccccc}
\hline Characteristic & $\begin{array}{c}\text { Mild } \\
(\mathrm{n}=22)\end{array}$ & $\begin{array}{c}\text { Moderate } \\
(\mathrm{n}=19)\end{array}$ & $\begin{array}{c}\text { Severe } \\
(\mathrm{n}=20)\end{array}$ & $\mathbf{p}$ \\
\hline Age (years) & $54.8 \pm 8.5$ & $52.8 \pm 9.155 .6 \pm 7.5$ & 0.5 \\
Duration of diabetes(years) & $8.2 \pm 6.8$ & $7.7 \pm 6.1$ & $6.1 \pm 5.3$ & 0.5 \\
BMI (kg/m²) & $25.5 \pm 3.6$ & $24.2 \pm 4.6$ & $22.6 \pm 3.4$ & $\mathbf{0 . 0 5}$ \\
HbA1C (\%) & $8.28 \pm 3.7$ & $9.9 \pm 4.2$ & $8.6 \pm 2$ & $\mathbf{0 . 0 1}$ \\
Total Cholesterol (mmol/l) & $4.5 \pm 1.9$ & $4 \pm 1$ & $4.2 \pm 1.1$ & 0.5 \\
Triglycerides (mmol/l) & $1.4 \pm 1.3$ & $1.1 \pm 0.5$ & $1.1 \pm 0.5$ & $\mathbf{0 . 0 0 0 0 1}$ \\
Tobaccouse n (\%) & $3(4.9 \%)$ & $1(1.6 \%)$ & $1(1.6 \%)$ & - \\
Alcoholuse n (\%) & $6(9.8 \%)$ & $7(11.5 \%)$ & $1(1.6 \%)$ & - \\
Dyslipidemia n (\%) & $11(18 \%)$ & $5(8.2 \%)$ & $4(6.5 \%)$ & - \\
Hypertension n (\%) & $13(21.3 \%)$ & $10(16.4 \%)$ & $8(13.1 \%)$ & 0.4 \\
\hline
\end{tabular}

$\mathrm{n}=$ number of cases.

bearable.

Other disorders associated with ED were mainly decreased or absent libido in 5 patients (8.2\%), premature ejaculation in 14 patients (22.9\%), delayed ejaculation in 10 patients (16, 4\%) and an ejaculation in 5 cases (8.2\%). Two patients (3.3\%) experienced penile pain during sexual intercourse. There was a performance anxiety in 56 patients (91.8\%), and 6 (9.8\%) patients reported difficulty with sleep.

In our series, 43 (70.5\%) patients received medical treatment. The remaining 18 (29.5\%) patients did not receive treatment either due to lack of funds or medical contraindications. Of the 31 patients who used the PDE5 inhibitors, 24 (77.4\%) patients experienced good therapeutic response, 6 (19.3\%) reported low response and one $(3.2 \%)$ found no change in symptoms. Twelve patients use dyohimbine, with 6 (50\%) reporting good response and 6 (50\%) reporting low response (Table 3 ).

In general, the average duration of treatment of erectile dysfunction was $19 \pm 9.8$ days with a range of1 and3 months for all agents used. Tolerance was good in 33 patients $(76.7 \%)$. However, 10 patients (23.6\%) experience dmultiple side effects with the use of phosphodiesterase type 5 inhibitors.

\section{Discussion}

The prevalence of erectile dysfunction in our study population was $57 \%$. In other studies found in the literature, the prevalence of erectile dysfunction in diabetic patients have reported ranging from $16 \%$ to $95.5 \%[2,3,6,7]$. The prevalence found in our study was similar to that reported by Costa et al. [8] in France who found a rate of $60 \%$. This is in contrast to Gueye et al. [9] in Se-
Table 3. Comparison of the efficacy of drugs on the IIEF5 erectile function score before and after treatment.

\begin{tabular}{ccc}
\hline Drugs & $\begin{array}{c}\text { IIEF-5 } \\
\text { before treatment }\end{array}$ & $\begin{array}{c}\text { IIEF-5 } \\
\text { after treatment }\end{array}$ \\
\hline Sildenafil & $12.8 \pm 4.1$ & $\mathbf{2 2 . 3} \pm \mathbf{4}$ \\
Tadalafil & $12.4 \pm 6.4$ & $\mathbf{1 8 . 6} \pm \mathbf{8 . 6}$ \\
Yohimbine & $13.8 \pm 4.5$ & $\mathbf{1 9 . 7} \pm \mathbf{3 . 9}$ \\
\hline
\end{tabular}

negal and Lokrou et al. [10] in the Ivory Coast who found a prevalence of $16 \%$ and $36.64 \%$ respectively. These results indicate the difficulty of evaluating ED (due to the use of different ED assessment tools), but may also be due to the small sample size of our study.

There was no association between marital status and the occurrence of erectile dysfunction $(\mathrm{p}=0.4)$. The number of wives was not significantly associated with the occurrence of ED in our study ( $\mathrm{p}=0.3$ ). Our results are different from those found by Gueye et al. [9] in Senegal, where $46.9 \%$ of patients were polygamous and $47.3 \%$ of men were monogamous. This difference could be due to the fact that Senegal is a predominantly Muslim country where polygamy is "encouraged".

All patients with ED had type 2 diabetes. The prevalence of type 2 diabetes can be explained by the "explosion" of this scourge worldwide [7,8,11-13], which, in Burkina Faso, can be partially explained by the increasing life expectancy among diabetics. Hypertension was found in more than half of our patients. This situation is explained by the fact that erectile dysfunction and hypertension share common etiologies such as endothelial dysfunction and atherosclerosis [14].

Throughout our study, obesity by BMI did not influence the occurrence of erectile dysfunction as has been described in other studies $[12,15,16]$. However, the number of obese patients in our series was potentially too low to determine any meaningful conclusions.

The influence of smoking in the occurrence of erectile dysfunction is controversial in the literature [16-19]. Our series and several other studies have not found a significant association between smoking and erectile dysfunction $[4,19]$. In contrast to other work, Fedele [7] in Italy, El-Achhab [15] in Morocco and Court et al. [20] in France have established an association between tobacco poisoning and occurrence of erectile dysfunction. Smoking potentiates the effects of chronic conditions favoring the development of endothelial dysfunction.

Alcohol consumption was not associated with the occurrence of erectile dysfunction in our study $(p=0.9)$ consistent with findings by Hsu et al. [13] in China, ElAchhab [15] in Morocco and Moulik et al. [21] in England.

The total cholesterol was significantly associated with the occurrence of erectile dysfunction in our study $(\mathrm{p}=$ 
0.02), as found in the work of Fedele et al. [7] in Italy. This association may be due to the occurrence of endothelial dysfunction in hyperlipidemia.

Sexuality still remains a taboo subject in our society and explainsour patients' silence (73.8\% of patients). Our results confirm the French study by Costa et al. [8] which found that $98 \%$ of patients think that health care professsionals should regularly ask the patient about his sexuality and sexual function. Other associated disorders such as decreased libido, premature or delayed ejaculation and an ejaculation reflect the fact that the onset of erectile dysfunction in diabetics is primarily organic, but with a significant psychological component, as reported by several authors in the literature [9,22].

The severity of ED was variously appreciated by patients and can be explained by the fact that some patients experience discomfort, or are reluctant to report certain items or check the IIEF-5 score. In our study, even though patient age was a variable associated with the onset of ED, there was no association between age and the severity of erectile dysfunction $(p=0.5)$. Diao [16], in Senegal, found that the severity of ED increases significantly with age. We noted no significant association between duration of diabetes and severity of erectile dysfunction in our study $(p=0.5)$. Our results are different from those of Siu [13] in China who reported that the time course of diabetes influenced the severity of ED. This difference could be justified by the fact that the average age of our patients was lower than the one of this author's patients.

If our patients were to suffer from this disorder for the rest of their lives, nearly three-quarters of our patients would consider this to cause variable degrees of pain and suffering. Numerous studies in non-diabetic patients across the world have shown that erectile dysfunction has a negative impact onpatients' relationships with their partners $[8,9,23,24]$.

The efficacy of the class of phosphodiesterase type 5 inhibitors in our series is consistent with that reported by Court et al. [20] in France, who found a success rate of $60 \%$ to $85 \%$. These high levels of satisfaction support the efficacy of these drugs against ED in diabetic patients. In the literature, yohimbine has been shown only to be effective in psychogenic dysfunction and is often tried as a second line drug [4]. In our study, yohimbine was offered to patients who had contraindications to PPDE-5 inhibitors, or those who could not afford the PPDE-5 inhibitors. The small number of patients using yohimbine in our series does not allow us to draw any statistically significant conclusions regarding its efficacy.

\section{Conclusion}

Erectile dysfunction is commonly found among patients with diabetes, especially among those with the type 2 designation. Its occurrence is influenced by hypertension and dyslipidemia. Phosphodiesterase type 5 inhibitors have been proven to be an effective treatment. To better implement this treatment, the need for collaboration between urologists and rologists, cardiologists, gynencologists, internists and sexologists, is crucial. A further prospective study should be conducted to assess the social impact of erectile dysfunction in diabetic patients in our context.

\section{REFERENCES}

[1] International Diabetes Federation (IDF), "Diabetes Atlas," 5th Edition, International Diabetes Federation, Brussels, 2011.

[2] R. Ma and P. Long, "Dysfonctionnement Erectile Chez les Hommes Atteints de Diabète: Signe Precoce de Cardiopathie,” Diabetes Voice, Vol. 53, No. 3, 2008, pp. 2527.

[3] J. Romeo, A. Seftel, Z. Madhun and D. Aron, "Sexual Function in Men with Diabetes Type 2: Association with Glycemic Control,” Journal of Urology, Vol. 163, No. 3, 2000, pp. 788-791. http://dx.doi.org/10.1016/S0022-5347(05)67805-6

[4] V. Phé, M. Rouprèt, K. Ferhi, O. Traxer, F. Haab and S. Beley, "Etiologie et Prise en Charge de la Dysfonction Erectile chez le Patient Diabétique,” Progrès en Urologie, Vol. 19, No. 6, 2009, pp. 364-371. http://dx.doi.org/10.1016/j.purol.2009.02.004

[5] R. C. Rosen, J. C. Cappelleri, M. D. Smith, J. Lipsky and B. M. Peña, "Development and Evaluation of an Abridged, 5-Item Version of the International Index of Erectile Function (IIEF-5) as a Diagnostic Tool for Erectile Dysfunction,” International Journal of Impotence Research, Vol. 11, No. 6, 1999, pp. 319-326.

[6] H. Awad, A. Salem, A. Gadalla, A. El wafa and O. Mohamed, "Erectile Function in Men with Diabetes Type 2: Correlation with Glycemic Control,” International Journal of Impotence Research, Vol. 22, No. 1, 2010, pp. 36-39. http://dx.doi.org/10.1038/ijir.2009.39

[7] D. Fedele, A. Bortolotti, C. Coscelli, F. Santeusanio, L. Chatenoud, E. Colli, M. Lavezzari, M. Landoni and F. Parazzini, "Erectile Dysfunction in Type 1 and Type 2 Diabetics in Italy," International Journal of Epidemiology, Vol. 29, No. 3, 2000, pp. 524-531.

http://dx.doi.org/10.1093/ije/29.3.524

[8] P. Costa, T. Grivel, F. Giuliano, P. Pinton, E. Amar and A. Lemaire, "La Dysfonction Erectile: Un Symptôme Sentinelle?” Progrès en Urologie, Vol. 14, 2005, pp. 203-207.

[9] S. Gueye, S. Diop, M. BA, E. Dagadou, P. Fall, M. Sow and A. Mensah, "La Dysérection Chez le Diabétique. Profil Epidemiologique au Sénégal,” Progrès en Urologie, Vol. 8, 1998, pp. 377-781.

[10] A. Lokrou, D. P. Koffi, S. Soumahoro, A. Derbé, J. Abodo, A. J. C. Azoh, et al., "Etude Epidémiologique et Clinique de la Dysfonction Erectile du Diabétique noir 
Africain en Côte d'Ivoire,” Diabetes \& Metabolism, Vol. 36, 2010, pp. A40-A109.

[11] M. D. Azemar, J. Menard, T. Ripert and F. Staerman, "Le Schema Thérapeutique Habituel de la Dysfonction Erectile Est-Il Adapté Après 65 Ans?” Progrès en Urologie, Vol. 19, No. 3, 2009, pp. 202-208. http://dx.doi.org/10.1016/j.purol.2008.11.010

[12] V. Fonseca, A. Seftel, J. Denne and P. Fredlund, "Impact of Diabetes Mellitus on the Severity of Erectile Dysfunction and Response to Treatment: Analysis of Data from Tadalafil Clinical Trials,” Diabetologia, Vol. 47, No. 11, 2004, pp. 1914-1923. http://dx.doi.org/10.1007/s00125-004-1549-6

[13] S. Siu, S. Lo, K. Wong, K. M. Ip and Y. Wong, "Prevalence of and Risk Factors for Erectile in Hong Kong Diabetic Patients," Diabetic Medicine, Vol. 18, No. 9, 2001, pp. 732-738. http://dx.doi.org/10.1046/j.0742-3071.2001.00557.x

[14] S. Droupy, “Dysfonction Erectile,” Revue du Praticien, 2010, pp. 685-728.

[15] Y. El Achhab, M. Berraho, A. Benslimane, M. Chrit, H. El Hassani, B. Lyoussi and C. Nejjari, "Diabète et Dysfonction Erectile au Maroc: Etude Epidemiologique Auprès d'une Population de Consultants,” La Revue de Santé de la Méditerranéeorientale, Vol. 14, No. 5, 2008, pp. 1090-1100.

[16] B. Diao, A. K. Ndoye, P. A. Fall, Y. Diallo, Y. Sow, B. Fall, L. Niang, A. Odzebe, I. Bah, M. Ba and B. A. Diagne, "La Dysfunctionerectile au Sénégal: Profil Epidémiologique, ”Androl, Vol. 17, No. 3, 2007, pp. 223229. http://dx.doi.org/10.1007/BF03040731

[17] P. Lyngdorf and L. Hemmingsen, “Hemmingsen Epidemiology of Erectile Dysfunction and Its Risk Factors: A Price-Based Study in Denmark," International Journal of Impotence Research, Vol. 16, No. 2, 2004, pp. 105-111. http://dx.doi.org/10.1038/sj.ijir.3901184

[18] E. Moreira, L. Lôbo, M. Villa, A. Nicolosi and D. Glasser, "Prevalence and Correlates of Erectile Dysfunction in Salvador, Northeastern Brazil: A Population-Based Study,” International Journal of Impotence Research, Vol. 14, Suppl. 2, 2002, pp. S3-S9. http://dx.doi.org/10.1038/sj.ijir.3900892

[19] R. Rosen, J. Altwein, P. Boyle, S. R Kirby, B. Lukacs, E. Meuleman, et al., "Troubles Urinaires du bas Appareil et Dysfonction Sexuelle Masculine: l'Enquête MSAM-7 ou Enquête Multinationale de l'homme Agé," Progrès en Urologie, Vol. 14, 2004, pp. 332-344.

[20] F. Cour, P. Fabbro-Peray, B. Cuzin, M. Bonierbale, P. Bondil, M. Crecy, et al., "Recommandations aux Médecins Généralistes pour la Prise en Charge de Première Intention de la Dysfonction Erectile,” Progrès en Urologie, Vol. 15, 2005, pp. 1011-1020.

[21] P. Moulik and K. Hardy "Hypertension, Antihypertensive Drug Therapy and Erectile Dysfunction in Diabetes," Diabetic Medicine, Vol. 20, No. 4, 2003, pp. 290-293. http://dx.doi.org/10.1046/j.1464-5491.2003.00911.x

[22] A. Allouch and J. J. Legro, "Les Troubles Erectiles Chez les Diabétiques à l'ABD,” Contacts-Diabète-Infos, Bruxelles, Vol. 50, 2002, pp. 935-1180.

[23] P. Costa, C. Avance and L. Wagner, "Dysfonction Erectile: Connaissances, Souhaits et Attitudes. Résultats D’une Etude Française Réalisée Auprès de 5099 Hommes âgés de 18 à 70 ans,” Progrès en Urologie, Vol. 13, No. 1, 2003, pp. 85-91.

[24] F. Giuliano, M. Chevret-Measson, A. Tsatsaris, C. Reitz, M. Murino and P. Thonneau, "Prévalence de L'insuffisance érectile en France: Résultants D’une Enquête EpidéMiologique Menée d'un Echantillon de 1004 Hommes,” Progrès en Urologie, Vol. 12, 2002, pp. 260-267. $\square$ 